Claves. Revista de Historia, Vol. 4, Nº 6

Montevideo, enero- junio 2018

(pp. 73 - 94) ISSN 2393-6584

\title{
Leis velhas, direitos novos: política popular e politização na revolta da Maria da Fonte ${ }^{1}$
}

Old laws, new rights: popular politics and politicization in the revolt of Maria da Fonte

Fátima Sá e Melo Ferreira

Instituto Universitário de Lisboa, Portugal

Recibido: 13/05/2018

Aceptado: 01/07/2018

Resumo: Neste artigo sustenta-se que a implantação do liberalismo em Portugal na primeira metade do século XIX trouxe ao mundo rural não apenas a transformação de quadros económicos e institucionais multisseculares através da desamortização da terra e da sua mercantilização, da reorganização administrativa do território, ou das novas políticas tributárias, mas também novas formas de protesto e de intervenção política.

A partir da análise de alguns conflitos que marcaram a grande revolta da Maria da Fonte em 1846, em particular os que se traduziram na expulsão de autoridades locais e na sua substituição por outras de nomeação popular, sugere-se que as lutas entre liberais e absolutistas e as internas ao liberalismo que se lhe seguiram, ao confrontarem o mundo rural com formas modernas de política ditaram também novas formas de “política popular”.

Palavras Chave: mundo rural , revolta, politização, "política popular”

\begin{abstract}
This article argues that the implantation of liberalism in Portugal in the first half of the 19th century brought to the rural world not only the transformation of centuries-old economic and institutional frameworks through the disentailment of land and its commercialization, the administrative reorganization of the territory, or new tax policies, but also new forms of protest

\footnotetext{
${ }^{1}$ Este artigo é uma revisão actualizada de "Modernização e conflito no mundo rural do século XIX, politização e 'politica popular' na Maria da Fonte”, publicado em História. Revista da Faculdade de Letras, série III, vol. 15, Porto, 2004, pp. 31-50.
} 
and political intervention. From the analysis of some conflicts that marked the great revolt of Maria da Fonte in 1846, in particular those that resulted in the expulsion of local authorities and in their replacement by others of popular nomination, it is suggested that the road between liberals and absolutists and the internal ones to the liberalism that was followed, when confronting the rural world with modern forms of politics, also gave new forms of "popular politics".

Keywords: rural world, revolt, politicization, "popular politics"

\section{Introdução}

No início do século XIX a maior parte da população portuguesa que vivia em território europeu não excedia no seu total os 3 milhões de habitantes e residia maioritáriamente nos campos ocupando-se principalmente na agricultura, a que se estima se dedicavam cerca de $60 \%$ dos activos, uma percentagem menor do que se poderia supor e inferior à de muitos outros países europeus o que traía o peso das actividades comerciais, portuárias e artesanais ligadas ao império.

O mundo rural foi, também por isso, um dos principais teatros das transformações jurídicas, económicas e sociais que as revoluções liberais trouxeram consigo, mesmo se muitas vezes as esquecemos e tendemos a imaginá-lo como um universo tendencialmente imóvel e pouco permeável à mudança. Na verdade, embora o principal impulso para a transformação política e para a instauração do liberalismo em Portugal a partir de 1820 tenha partido das duas principais cidades do país, Porto e Lisboa, as populações rurais envolveram-se desde cedo nesse processo, mobilizadas frequentemente pelas forças contra-revolucionárias e constituindo-se em guerrilhas que combateram numa espécie de guerra civil intermitente, antes e depois da guerra civil clássica na qual, entre 1832-1834, se confrontaram dois exércitos organizados em torno de dois projectos políticos alternativos, o liberal e o absolutista. Dois projectos que se corporizavam em dois irmãos rivais divididos pela política e pelos direitos de sucessão ao trono: D. Pedro herdeiro do trono português e primeiro Imperador do Brasil e D. Miguel, seu irmão mais novo, cuja ascensão ao trono em 1828 os contra-revolucionários apoiaram liderados pela sua mãe D. Carlota Joaquina de Bourbon e Bragança. 
Depois de 1834, com a vitória definitiva dos constitucionais, o país continuou dividido quer pelas antigas fracturas que pouco depois do fim da guerra reacenderam vários focos de oposição armada ao novo regime, sob a forma de guerrilhas que se reclamavam de D. Miguel, quer pelas que opuseram moderados e exaltados no interior do campo liberal. Em qualquer caso, a vitória do liberalismo em 1834 implicou a transformação mais ou menos acelerada de quadros institucionais multisseculares, através de fenómenos como a extinção dos dizimos e de parte dos direitos senhoriais, a desamortização da terra e a sua progressiva mercantilização, a reorganização administrativa do território, ou as novas políticas tributárias. ${ }^{2}$

Se hoje é pacífica a ideia de que as transformações que o Estado Liberal promoveu no sentido da racionalização dos velhos quadros políticoadministrativos, da homogeneização das estruturas fundiárias e tributárias e da expansão do mercado, é bom ter também presente que a par destas mudanças que habitualmente situamos no plano das estruturas sócio-económicas, outras, menos faladas mas não menos significativas, tiveram lugar. A politização das populações rurais e a nacionalização da política, podem considerar-se também indissociáveis não só das novas estruturas do poder liberal e do seu exercício, como as Cortes electivas ou as eleições propriamente ditas, mas também da dinâmica da criação do estado nacional e do reforço do poder do estado na esfera local e dos próprios conflitos políticos que tinham sacudido o país mantendo-o em guerra por cerca de catorze anos.

A nacionalização da política, a que Maurice Agulhon consagrou há muitos anos um estudo hoje clássico intitulado La République au village3, teve como corolário a politização do mundo rural, mesmo se em Portugal ou em Espanha o processo revestiu características bem diferentes das que assumiu em França. $\mathrm{O}$ facto de na Península Ibérica a "política na aldeia", ou seja, a penetração da política nacional na ordem local, ter ficado em larga medida refém, na segunda metade do séc. XIX, dos laços intrincados do "caciquismo", não significa que as novas práticas políticas não representassem uma profunda inovação para a

2 Nota do Editor: veja no final deste artigo um mapa de Portugal (ca. 1780) com a identificação das províncias e um outro com os distritos criados em 1835.

3 AGULHON, Maurice, La République au village, Paris, Plon, 1970. 
sociedade rural e não devam ser consideradas, nesse sentido, modernizadoras4. As estruturas "caciques" da política no mundo rural, que caracterizam as relações entre política local e política nacional, não só no contexto português, mas também, sob formas próximas, noutros países do Sul da Europa são, no fundo, uma das mais acabadas expressões do constante vai e vem entre o local e o nacional que se encontra no cerne da sociedade rural oitocentista, tanto em França como em Portugal como noutros países europeus, ainda que de modos diversos.

Ainda no quadro peninsular, é necessário ter presente que os longos e conflituosos processos de implantação dos estados liberais e as lutas civis que os acompanharam, envolvendo profundamente a sociedade rural e os camponeses, constituíram também uma outra forma, violenta e precoce, de nacionalização da política e de politização de muitas comunidades rurais.

As guerras civis e a incorporação das populações dos campos nesses conflitos através do exército regular, dos corpos de Voluntários realistas ou liberais e, no caso português, das Milícias e dos corpos de Ordenanças, vão trazer precocemente a política a muitas aldeias, mobilizando os habitantes de algumas regiões de forma persistente e duradoura em movimentos que não devem ser confundidos com anteriores formas de protesto colectivo. A formação e actuação de guerrilhas em várias regiões do país, antes e depois da guerra civil de 1832-34, é uma das melhores ilustrações desse fenómeno.

No entanto, apesar da historiografia actual já nos permitir entrever, de forma relativamente definida, os contornos de muitas das transformações e conflitos de natureza política que o mundo rural conheceu ao longo do séc. XIX, a relação da sociedade rural com a mudança social oitocentista continua ainda a ser equacionada, nos seus vários planos, quase exclusivamente em termos de resistência: resistência à mudança, resistência à modernização.

A persistência da perspectiva da resistência à modernização e à mudança como principal ferramenta analítica dos movimentos que afectaram o mundo rural português no séc. XIX, mesmo se aplicada somente aos que envolveram os seus sectores mais pobres, como os pequenos camponeses e os jornaleiros, não

4 ALMEIDA, Pedro Tavares de, Eleições e caciquismo no Portugal oitocentista (1868-189o), Lisboa, Difel, 1991. 
pode ser lida apenas como uma generalidade ou um lugar comum historiográfico. Pesquisas tão sistemáticas e aprofundadas como as que serviram de base à obra que José Viriato Capela consagrou à revolta rural conhecida pelo nome de Maria da Fonte, que eclodiu no Norte do país na primavera de 1846, publicada com o título de A Revolução do Minho de 1846. Os difíceis anos de implantação do Liberalismo ${ }^{5}$ parecem reforçá-la dado o peso que a hostilidade à inovação detém no vasto leque de questões com que o autor a relaciona . Ao percorrê-las, a resistência do mundo rural à mudança parece impor-se mais uma vez como uma evidência.

Assim, para além dos tópicos mais conhecidos como a hostilidade contra as leis da saúde que proibiam o enterro dos mortos nas igrejas determinando a construção de cemitérios, e contra a nova política tributária expressa na resistência ao imposto de repartição e ao novo imposto das estradas, vemos perfilarem-se outras questões em que o conflito parece poder ser simplesmente interpretado como recusa da inovação. É o caso da hostilidade face às reformas administrativas que desde 1836 procuravam racionalizar a divisão do território conduzindo à eliminação de muitos pequenos concelhos, ou às reformas judiciais.

O facto destas manifestações de hostilidade terem já alimentado múltiplos conflitos durante toda a década anterior parece sublinhar o carácter estrutural da recusa e reforçar ainda mais a perspectiva da resistência dos campos à mudança modernizadora. Na verdade, antes da revolta do Minho, nos dez anos que se seguem à guerra civil de 1832-34 que procurei analisar em Rebeldes e Insubmissos. Resistências Populares ao Liberalismo 1834-18446 é possível identificar manifestações de hostilidade bastante semelhantes às que se exprimirão na Maria da Fonte envolvendo muitas vezes as mesmas regiões. Encontramos exemplos significativos dessa continuidade na contestação das primeiras leis da saúde pública datadas de 1835, ou nos protestos levantados pela extinção de concelhos ou na contestação de novos impostos municipais e

5 CAPELA, José Viriato, A revolução do Minho de 1846. Os difíceis anos da implantação do liberalismo, Braga, Governo Civil de Braga, 1997.

${ }^{6}$ FERREIRA, Maria de Fátima Sá e Melo, Rebeldes e Insubmissos. Resistências populares ao liberalismo, 1834-1844, Porto, Afrontamento, 2002. 
estatais, contestação que gerou, por vezes, movimentações populares bastante intensas.

No imediato pós-guerra muitas dessas manifestações tumultuárias foram vistas pelas autoridades como sendo apenas ditadas pelo "mau espírito" político de algumas populações, "vencidas, mas não convencidas”, que decorria da sua fidelidade a D. Miguel, uma vez que a reivindicação do miguelismo continuou a alimentar, até ao início dos anos 40, movimentos mais estruturados e duradouros como as guerrilhas e, por isso mesmo, mais difíceis de arredar do universo político. Mas a liquidação da resistência miguelista no início dos anos 40 faz regressar definitivamente a análise dos conteúdos do protesto e da conflitualidade nos campos, pelo menos daqueles que foram protagonizados pelos sectores socialmente mais modestos da sociedade rural, ao universo do protesto social e do choque cultural sem qualquer conteúdo político.

Na revolta do Minho é clássico separar a conflitualidade local e apolítica das camadas rurais, que se manifestara nos momentos iniciais da revolta, da conflitualidade política e nacionalmente integrada que opunha as oposições coligadas ao governo conservador de Costa Cabral. Uma oposição que rapidamente teria vindo enquadrar as primeiras revoltas contra os cemitérios e a reforma tributária, através da formação das primeiras Juntas de governo locais.

Nesses conflitos os meios de acção utilizados, desde os enterros tumultuários nas igrejas às queimas dos registos das contribuições, remeteriam, também eles, para formas arcaicas de acção colectiva, para aquelas explosões violentas e episódicas que, nas sociedades do Antigo Regime, pontuavam ciclicamente o mundo rural em momentos de crise. O apelo ao regresso das "leis velhas", que ecoou várias vezes na Maria da Fonte, exprimiria emblematicamente o sentido do protesto.

Estas concepções sobre o sentido da conflitualidade no mundo rural oitocentista são ainda confortadas pelo facto de, no período posterior à Maria da Fonte, voltarmos a encontrar conflitos e tumultos muito semelhantes aos que se registaram naquela época, tanto relativamente aos alvos como aos meios de acção utilizados. Assim, sabemos, por exemplo que, em 1868, durante a chamada revolta da Janeirinha, o mundo rural voltou a contestar violentamente 
os tributos em várias localidades do Norte e do Centro do país onde se "assaltaram repartições da Câmara e da Fazenda escaqueirando-se móveis e lançando-se fogo a papéis"

Clara manifestação da resistência do mundo rural à modernização seria ainda a que foi oposta, de forma aparentemente mais pacífica, mas muito persistente, à introdução do sistema métrico decimal ${ }^{8}$.

Embora não haja evidência de que a questão tenha dado origem a importantes movimentos revoltosos como os dos chamados "quebra-quilos" no Brasil, sabe-se que a obrigatoriedade do novo sistema, adoptada em 1862, provocou distúrbios nalgumas localidades, como aconteceu por exemplo em Guimarães onde os novos pesos e medidas foram destruídos. A exaltação popular no decurso desses acontecimentos levou a vereação a afirmar ter havido "grave receio" de que a "a Vendeia se desse" naquela terra9. Também aqui o protesto se estendeu aos impostos e os arquivos das repartições públicas estiveram mais uma vez em risco.

\section{Leis velhas, direitos novos}

No entanto, se a ebulição que viveu o mundo rural português no séc. XIX e de que demos aqui alguns breves exemplos desmente, por si só, a ideia do imobilismo dos campos, algumas das expressões da conflitualidade que os sacudiu permitem também constatar que o conceito de "resistência à mudança" nos conduz a perspectivas empobrecedoras e no limite redutoras da acção colectiva das camadas rurais.

Na verdade, mesmo em momentos considerados tão característicos da resistência do mundo rural às transformações trazidas pela implantação do Estado Liberal como a revolta da Maria da Fonte, os camponeses não se limitaram a queimar os registos dos novos impostos e a clamar pelas "leis velhas". Em várias localidades da província do Minho as populações insurrectas pretenderam também exercer um direito novo, que a lei eleitoral lhes negava,

\footnotetext{
7 CUNHA, Carlos Guimarães da, A "Janeirinha e o Partido Reformista. Da revoluçãp de Janeiro de 1868 ao pacto da Granja, Lisboa, Edições Colibri, 2003, pp. 80-81.

8 JUSTINO, David, A formação do espaço económico nacional- Portugal, 181o-1913, Lisboa, Editorial Vega, 1988-1989, 2 vols.

9 JUSTINO, David, A formação do espaço..., ob. cit., vol. II, p. 198.
} 
depondo as autoridades locais ligadas ao anterior governo e substituindo-as por outras de sua eleição.

O alargamento, em trabalhos recentes, da base documental que durante muito tempo serviu de referência à análise da revolta da Maria da Fonte permite hoje reequacionar questões já anteriormente assinaladas, mas cuja aparente singularidade deixava escapar grande parte do seu significado. É o caso da defesa do princípio da "eleição geral e universal de todos os cargos e empregos" empreendida pelo Padre Casimiro José Vieira, um eclesiástico que comandou as forças populares e foi seu porta-voz embora sendo miguelista, na sua não menos célebre carta à Rainha D. Maria II datada de Junho de 1846 e posteriormente incluída nas suas memórias. ${ }^{10}$

Dispomos hoje de muito mais informação sobre a expulsão e a perseguição de autoridades que envolveram muitas das acções populares praticamente desde os inícios da revolta tendo como principais alvos os administradores dos concelhos e os juízes de direito, acções geralmente acompanhadas pela designação de novas autoridades pelas populações insurrectas.

Logo no início dos acontecimentos, no mês de Abril de 1846, são assinalados fenómenos desta natureza em pelo menos seis sedes de concelho da provincia do Minho no norte do país: Ponte da Barca, Barcelos, Póvoa do Varzim, Vila do Conde, ${ }^{11}$ Amarante $^{12}$ e Guimarães ${ }^{13}$.

Nos relatórios oficiais em que se dá conta destas acções nem sempre é referido com detalhe o processo de designação das novas autoridades e é por vezes também omissa a identidade dos designados, mas dispomos, no entanto, de alguns relatos esclarecedores.

\footnotetext{
10 Apontamentos para a história da revolução do Minho em 1846 ou da Maria da Fonte, escriptos pelo Padre Casimiro finda a guerra em 1847, Lisboa, Edições Rolim, s/d. (Prefácio de José Manuel Sobral).

${ }^{11}$ CAPELA, José Viriato, A revolução do Minho de 1846. Os difíceis..., ob. cit.

${ }_{12}$ CAPELA, José Viriato, A revolução do Minho de 1846 segundo os relatórios de Silva Cabral e Terena José, Porto, Afrontamento, 1999.

13 ESTÊVÃO, João Antunes, "Guerrilhas na Serra da Lameira e guerrilhas de Fafe. Antropologia da violência rural”, Actas das II Jornadas de História Local, Fafe, Câmara Minicipal de Fafe, 1998.
} 
Em relação a Vila do Conde sabemos, por exemplo, que a nomeação de novas autoridades foi feita por uma guerrilha que entrou na vila em força com cerca de 200 a 300 homens armados de espingardas e instrumentos agrícolas originários, na sua maior parte, de uma freguesia rural do concelho de Barcelos. Eram comandados por um indivíduo que fora porta-bandeira das milícias da própria Vila do Conde e por um ex-capitão de Ordenanças da freguesia de Cervães do concelho do Prado. A guerrilha nomeou Câmara, juiz e administrador e queimou os impressos da contribuição directa que havia na administração. Não sabemos, porém, quem foram os designados nem como se procedeu à sua nomeação ${ }^{14}$.

Na Póvoa do Varzim foram constituídas também novas autoridades camarárias, presidente e vereadores, e ainda juiz ordinário, administrador e escrivão da administração. O relatório de José da Silva Carvalho dirigido à Rainha que relata os factos refere alguns dos nomes dos novos nomeados, mas indica também que nenhum aceitou as funções com excepção de um escrivão ${ }^{15}$.

Sobre Ponte da Barca sabemos que os revoltosos (a quem a autoridade concelhia que assina o ofício chama "os incendiários") depois de assaltarem a alfândega, a administração e a recebedoria do concelho queimando documentos e móveis, nomearam administrador do concelho e juiz de fora respectivamente o escrivão do juiz de paz e o escrivão da Câmara da vila ${ }^{16}$.

Em Guimarães, o ex-escrivão do judicial, Valentim Moreira de Sá, demitido pela antiga administração Cabralista, foi "aclamado" administrador do concelho $^{17}$ e em Barcelos a escolha para esse mesmo cargo recaiu no "Dr. Valença, ex-delegado daquela Comarca"18. Nos últimos casos referidos, os indivíduos que vieram substituir as autoridades constituídas eram geralmente tidos por pertencentes às Comissões oposicionistas ou "conhecidos pelos seus sentimentos contrários às actuais instituições”.

\footnotetext{
14 CAPELA, José Viriato, A revolução do Minho de 1846 segundo os relatórios...ob. cit., p. 102.

15 Ibidem, p. 103.

${ }^{16}$ CAPELA, José Viriato, A revolução do Minho de 1846. Os difíceis..., ob. cit., p. 200.

${ }_{17}$ ESTÊVÃO, João Antunes, ob. cit., p. 245.

${ }_{18}$ CAPELA, José Viriato, A revolução do Minho de 1846. Os difíceis..., ob. cit., p. 203.
} 
No Alto-Minho, parece ter havido também substituições de autoridades na zona dos Arcos. Aqui a revolta, apontada como sendo dirigida por António Sá Sotto-Mayor, um célebre ex-capitão de milícias, terá assumido claros contornos miguelistas: gritaram-se vivas a D. Miguel e as novas autoridades foram constituídas com os títulos de juízes de fora e provedores, designações anteriores ao regime liberal ${ }^{19}$.

Promover localmente a substituição revolucionária das autoridades "cabralistas", ou seja designadas pelo ministério conservador dirigido por Costa Cabral, por outras saídas dos círculos da oposição era, sem dúvida, um método expedito para acelerar a queda do governo.

O governo caiu, de facto, um mês depois, a 20 de Maio, num momento em que a intervenção da coligação oposicionista, que se formara aquando da chegada de Cabral ao governo em 1842, já passara para uma nova fase: a da formação das Juntas de Governo locais. Tais organismos integravam geralmente membros das elites distritais e municipais e não se formaram apenas nas províncias do Norte, onde a insurreição começara, mas no conjunto do território continental ${ }^{20}$. Nas Juntas as oposições dominavam, contando algumas delas na sua direcção figuras de grande relevo do setembrismo e do miguelismo, as principais forças que se tinham aliado desde 1842 na comissão eleitoral denominada“Coalisão”.

Mas se as oposições coligadas se aquietaram e as Juntas se dissolveram com relativa celeridade após a queda do governo de Costa Cabral, "os povos" permaneceram agitados apesar de ter sido decretada a suspensão das leis da saúde pública e dos impostos de repartição, alvos mais visíveis da contestação popular.

A continuação dos protestos durante o governo formado após a queda de Costa Cabral e chefiado pelo moderado duque de Palmela não é aliás um fenómeno desconhecido, embora, de uma maneira geral, a historiografia que o assinala não se tenha detido muito na sua apreciação. As mais recentes contribuições para o estudo da revolta do Minho permitem, porém, perceber

19 CAPELA, José Viriato, A revolução do Minho de 1846 segundo os relatórios...ob. cit., p. 103. 20 OLIVEIRA, Luísa Tiago de, “A Maria da Fonte e a Patuleia. Alguns problemas”, Ler História, $\mathrm{n}^{0} 16,1989$, pp. 159-174. 
algumas linhas de força dessas motivações que claramente se situam no terreno da política e não só, ou não apenas, no terreno ocupado pela reacção miguelista expressa na actuação de guerrilhas locais que se pronunciavam "em favor do Usurpador" ou, mais tarde, na frustrada tentativa de insurreição protagonizada pelas forças do General MacDonell ${ }^{21}$.

\section{"Exigências intoleráveis"}

Os alvos da agitação popular depois da queda do governo e da suspensão das leis mais contestadas parecem situar-se na continuidade das aç̧ões de hostilidade contra os agentes locais da administração Cabralista que se manifestavam desde o mês de Abril, na expulsão de autoridades e na sua substituição, embora existam diferenças significativas no teor das reivindicações populares.

Os empregados públicos e as autoridades do Cabralismo que ainda permaneciam em funções continuam, de facto, a ser alvo de ataques violentos como os que ocorreram na vila dos Arcos a 8 de Junho e em Ponte de Lima a 19. Nessa vila, por exemplo, "entraram armados [...] os povos do Soajo e logo em seguida os de algumas freguesias do concelho com o fim de obrigarem as autoridades e empregados antigos já suspensos a retirarem-se da vila onde não os queriam ver nem consentir ameaçando prendê-los e assassiná-los se dentro de 24 horas as novas autoridades os não mandassem sair para fora do concelho"22. Ponte de Lima foi, por seu turno, invadida pelos "povos de Lage e de outros concelhos vizinhos em $\mathrm{n}^{0}$ de 600 e tantos homens com o fim de destituírem e deporem todas as autoridades e empregados antigos que ainda funcionam $[\ldots]]^{\prime 23}$.

Em meados do mês, no Distrito de Braga, tido por "geralmente pacificado", o governador civil referia também a persistência da hostilidade contra os empregados, neste caso os "empregados judiciários", alegando não ser

${ }^{21}$ CAPELA, José Viriato, A revolução do Minho de 1846. Os difíceis..., ob. cit.; BRISSOS, José, A insurreição miguelista nas resistências a Costa Cabral (1842-1847), Lisboa, Edições Colibri, 1997; LOUSADA, Maria Alexandre; FERREIRA, Maria de Fátima Sá e Melo, D. Miguel, Mem Martins, Círculo de Leitores, 2006.

${ }^{22}$ CAPELA, José Viriato, A revolução do Minho de 1846. Os difíceis..., ob. cit.

23 Ibidem. 
possível "estabelecer audiências pelo ódio que inspiram ao povo (...) com pequenas excepções".

Poucos dias depois, o mesmo governador civil mostrava-se mais inquieto quanto à conservação da tranquilidade na província já que: “(...) os povos dos concelhos ao Norte e Nascente estão altivos com a vitória, e fascinados por alguns intrigantes se reúnem armados e fazem exigências intoleráveis e abertamente se pronunciam contra a conservação de todos os empregados quer judiciais quer administrativos inclusive juízes de direito e ordinários". Informava também que, mesmo tendo aceite as novas autoridades por ele nomeadas, "à voz do primeiro intrigante se reúnem em torno dela" sendo necessária toda a sua influência "para os conter e fazer recolher a suas casas".

Para além desta pesada vigilância sobre as autoridades locais, os povos davam ainda a conhecer "a perigosa pretensão de todos votarem nas próximas eleições"24. Compreendemos assim um pouco melhor a anterior referência a "exigências intoleráveis" e o novo alcance das reclamações.

Por informação posterior do governador civil do Porto ficamos a saber que na vizinha província de Trás-os-Montes a agitação popular ganhava claros contornos miguelistas. Em vários concelhos registavam-se "Vivas ao Usurpador, acompanhados de Te Deum, tumultos, reuniões de gente armada e geralmente desobediência às autoridades constituídas e nomeações de juízes de vintenas, etc." Não teria havido, no entanto "perseguições nem insultos aos liberais porque muitos têm atravessado sem perigo os diferentes grupos".

No Distrito de Braga, onde os gritos em favor de D. Miguel quase não tinham encontrado eco, nem por isso a situação deixava de inspirar receios. Segundo o governador civil, em ofício de 9 de Julho, o sossego era uma "falsa aparência" porque "a plebe afeita a três meses de licença desregradíssima recalcitra apenas se lhe apresenta o jugo da lei, mais justa e santa que seja”. Na opinião da mesma autoridade a cobrança de todo e qualquer tributo não se iria poder efectuar sem recurso ao uso da força. Mais uma vez a questão das eleições era apresentada como central: "as eleições municipais serão revoltosas se não

24 CAPELA, José Viriato, A revolução do Minho de 1846. Os difíceis..., ob. cit. 
lhes for concedido elegerem também juízes ordinários como já tive ocasião de expor a Va. Ex. ${ }^{a} " 25$.

A nomeação popular das autoridades locais conhecia pouco depois novos desenvolvimentos. Em Ruivães, onde a 14 de Junho os povos tinham designado novas autoridades fixando em acta a sua decisão, vieram dar-lhes posse um mês depois cerca de 100 homens de algumas freguesias que o integravam: "a chamo e ordem do célebre Padre Casimiro". A acção foi acompanhada pela entrega aos nomeados de todos os papéis que havia na Administração e no Juízo ordinário. O administrador interino de Ruivães completava a descrição dos novos desacatos referindo que os membros da Câmara, o administrador, o juiz ordinário e o subdelegado eram agora "todos homens rústicos a maior parte deles empregados no fabrico de azeite no Alentejo, no tempo da colheita". Mesmo tendo assinalado a intervenção do Padre Casimiro, o administrador asseverava não haver "partido político nestes revoltosos; o seu fim principal é fazer constituir autoridades suas" 26 .

Mas é em fins de Junho que o ponto mais alto da contestação das autoridades locais parece ser atingido. Nesta altura o governador civil informava o governo de estarem os povos do seu distrito "em perfeita insurreição perseguindo e expulsando todos os empregados públicos ainda mesmo os juízes de direito", acrescentando terem as novas autoridades "a maior dificuldade em os conter" tendo algumas delas sido também expulsas, "não querendo os povos para os governar senão indivíduos das próprias terras e por eles nomeados”. O padre Casimiro era mais uma vez referido como chefe da revolta e descrito como "desafecto à Rainha e à Carta". No entanto, os distúrbios provocados pela perseguição às autoridades não são ainda considerados manifestações de carácter miguelista. Sabendo-se que pouco antes D. Miguel fora aclamado em Montalegre "por alguns padres e pessoas de pouca importância" o governador de Braga, no mesmo ofício em que refere os tumultos contra os empregados

${ }_{25}$ CAPELA, José Viriato, A revolução do Minho de 1846. Os difíceis..., ob. cit. ${ }^{26}$ Ibidem. 
públicos, acrescenta que "o grito de Montalegre não teve eco no Distrito", embora tivessem aí também aparecido agitadores miguelistas ${ }^{27}$.

Pela mesma época o governador do distrito de Viana confrontava-se também com acções semelhantes. Alguns povos daquela região tinham "procedido como os de Braga ou talvez com mais violência a respeito dos empregados, tendo havido grandes dificuldades em evitar efusão de sangue particularmente em Ponte de Lima, Arcos, Barca e Soajo". As autoridades julgavam "necessária e urgente a demissão ou transferência de todos os empregados judiciais das comarcas referidas e a nomeação ou confirmação dos eleitos pelo povo"28.

De acordo com o único exemplo que é referido com algum detalhe, o de Ponte de Lima, os empregados expulsos teriam sido substituídos pelos que tinham sido demitidos pela administração Cabralista pelo próprio governador civil. Julgava-se ainda necessária a transferência de todos os juízes de direito do distrito, excepto os de Viana e Monção, não só para manter a ordem pública, mas também para garantir a sua segurança pessoal.

Lado a lado com as questões relativas à participação popular na designação das autoridades locais vão-se tornando mais nítidas as novas frentes do combate contra os impostos. A 20 de Julho, em Terras do Bouro, os povos amotinaram-se e dirigiram-se a casa do ex-recebedor exigindo-lhe que lhes fosse devolvido o cruzado que tinham pago para as estradas pretextando que "no concelho de St. a Marta se fizera já esta entrega". De acordo com o relato do governador civil de Braga: "dali dirigiram-se a casa do ex-administrador do concelho e do ex-presidente da Câmara para que lhes entregassem as secretarias respectivas, exigindo também do administrador do concelho o excesso de uns emolumentos que lhes levara demais”29.

\footnotetext{
27 Ibidem, p. 223. Deve referir-se que, como notou José Brissos, a actuação do Padre Casimiro neste período era inteiramente alheia aos planos de insurreição miguelista em curso desde 1843 e que iriam pôr-se em marcha, sob o comando de MacDonell, a partir de Novembro de 1846. Segundo o mesmo autor só nos finais desse mês e no contexto da ocupação de Braga é que se deu a integração da guerrilha do Padre Casimiro na tentativa de restauração miguelista. BRISSOS, José, ob. cit., pp. 102 e 119.

${ }^{28}$ CAPELA, José Viriato, A revolução do Minho de 1846. Os difíceis..., ob. cit., p. 224.

29 Ibidem, p. 219.
} 
Alguns dias depois, o governador civil tranquilizou o governo quanto às exigências de devolução de impostos recebidos: não só este tipo de exigência não se tinha estendido a outros concelhos, mas nem mesmo em Terras do Bouro se tinha consumado a devolução. No entanto, segundo esta mesma autoridade, aquele imposto que subsistira, era tão "odiado pelo povo em todo este Distrito" que não reputava prudente "na actualidade, e enquanto durar o presente estado vertiginoso dos povos, o fazer-se cobrar para o que nem haverá a necessária força tão geral é a indisposição contra ele" 3 .

O governador já anteriormente informara o Ministro dos Negócios do Reino de que os povos se recusavam agora a pagar "os tributos legais" e que os principais alvos da contestação eram o subsídio literário e o cruzado para as estradas, sugerindo mesmo que fossem aliviadas aquelas duas contribuições para que se pudessem cobrar as principais, ou seja, o imposto da décima.

Em meados de Agosto a situação do Distrito de Viana parecia bastante mais controlada, visto que o governador informava os seus superiores de que na região a seu cargo continuava a "reinar o sossego". No entanto, poucos dias antes, o concelho de Esposende tinha ainda sido teatro de mais uma acção de expulsão de autoridades do tempo da administração anterior, nomeadamente o juiz ordinário e o recebedor. O governador civil aproveitava o mesmo ofício para referir os receios dos administradores de Esposende e Barcelos de que "se repitam e propaguem actos de tão obnóxia natureza" ${ }^{31}$.

Nos inícios de Setembro era Ruivães que voltava a agitar-se sendo que "um dos principais motivos do descontentamento daqueles povos" era não quererem "admitir as autoridades que para ali nomeou a Junta de Vila Real e sim os da sua escolha cuja relação, dada pelos mesmos povos, foi pelo General remetida ao Governador Civil de Vila Real" ${ }^{2}$. Tratava-se certamente dos mesmos "rústicos" que tinham sido empossados em meados de Julho.

Noutros pontos do país viviam-se situações semelhantes que Miriam Halpern Pereira identificou através da Correspondência mantida entre o Ministério do Reino e a Câmara dos Deputados, de 21 de Maio a 6 de Outubro

\footnotetext{
30 CAPELA, José Viriato, A revolução do Minho de 1846. Os difíceis..., ob. cit., pp. 220-221.

${ }^{31}$ Ibidem, p. 221.

32 Ibidem, p. 222.
} 
de 46, ou seja, entre a queda do governo de Costa Cabral e a célebre "Emboscada" 33 " que iria dar início à guerra civil da Patuleia34.

Nos tumultos que esta autora refere, onde se destacam mais uma vez os que tinham por alvo os impostos, nomeadamente o subsídio literário, o imposto para as estradas e os impostos municipais, as destituições de autoridades locais ocuparam também um lugar de relevo. Do distrito de Aveiro, a sul do Douro ao de Faro no extremo sul do país são citadas várias localidades agitadas por processos da mesma natureza, como é o caso de Vila da Feira onde a resistência das autoridades à expulsão acarretou cinco dias de desordens, ou o de Santiago do Cacém onde foi necessário recorrer à força militar para impor um novo administrador de concelho, ou o da Lourinhã onde as autoridades designadas pelas populações se mantiveram em função durante dois meses 35 .

No entanto continua a faltar uma investigação mais aprofundadada sobre a Maria da Fonte nas províncias a sul do Douro para obtermos uma imagem mais exacta da cronologia e da geografia destes acontecimentos assim como da sua dinâmica local e regional.

\section{Conclusões provisórias}

Se a singularidade da dinâmica política da Maria da Fonte deve ser assinalada com vista a novas pesquisas, pode, ainda assim, considerar-se que os exemplos recolhidos autorizam desde já algumas conclusões provisórias.

Em primeiro lugar esses exemplos permitem sugerir que mesmo se a reinvindicação da nomeação popular das autoridades locais foi feita por um eclesiástico miguelista como o Padre Casimiro, quando defendeu na carta à Rainha D. Maria II o princípio da eleição geral e universal de todos os cargos e empregos, eles demonstram que a aspiração à sua designação pelas populações estava vulgarizada no mundo rural, do norte do país, em particular na província

\footnotetext{
33 "Emboscada" foi o nome porque ficou conhecido o golpe de estado palaciano pelo qual a Rainha D. Maria II substituiu o governo moderado chefiado pelo Duque de Palmela e que integrava elementos da oposição, por um novo governo conservador, afecto a Costa Cabral, embora sem a presença deste contestado ministro. A oposição reagiu formando uma junta governativa no Porto que não acatava as ordens do novo governo . Esta dissidência deu origem a breve trecho à guerra civil da Patuleia entre a Junta do Porto e o governo de Lisboa

34 PEREIRA, Miriam Halpern, ob. cit.

35 Ibidem, pp. 26-27.
} 
do Minho, não devendo por consequência ser vista como um mero desideratum de um clérigo miguelista ${ }^{36}$.

Em segundo lugar, a observação conjunta de alguns destes processos sugere igualmente, como escreve José Capela, que a reacção contra as autoridades locais , embora expressa por um padre afecto a D. Miguel, "não deixou de constituir também uma das principais contribuições para as correntes e os partidos progressistas, que partindo de formas mais antigas de contestação generalizada às autoridades políticas transformaram as ideias tradicionalmente conservadoras dos direitos populares numa doutrina progressista da soberania popular"37. A articulação entre as nomeações populares de autoridades e os "partidos progressistas" reporta-se neste caso, à presença activa dos setembristas, ala esquerda do liberalismo, no decurso da revolta. Nesse sentido, vale a pena insistir na ideia de que a difusão nas províncias do setembrismo, de que se podem entrever alguns episódios nos 10 anos que se seguiram à guerra civil, deve merecer uma atenção maior do que que a que lhe tem sido concedida ${ }^{3}$.

Em terceiro lugar, merece a pena referir também que, mesmo se as atitudes populares em relação aos empregados e funcionários da administração local traduziram muitas vezes explicitamente a recusa da ingerência na vida das comunidades de poderes que lhe fossem exteriores, como também acentua José Capela, tal facto não nos autoriza por si só a classificar uma vez mais estas formas de acção e reivindicação como "resistências à modernização", nem a tomá-los como indícios da aspiração ao regresso das velhas formas da administração local que o liberalismo tinha vindo substituir.

Mesmo sendo verdade que a eleição das administrações camarárias no Antigo Regime era um processo que apresentava um grau apreciável de diversidade de acordo com as características dos concelhos considerados, é

\footnotetext{
${ }^{36}$ É útil relembrar os termos exactos em que na carta que o Padre Casimiro dirigiu à Rainha é colocada a questão da eleição das autoridades locais: "Pedimos, Real Senhora, que as eleições para toda a espécie de justiça e authoridades sejam de todo populares sem excepção de pessoa, a não ser que não lêem nem escrevem, para evitar enganos e despertar a instrucção; porque só assim se pode exprimir a vontade geral dos povos, que é a verdadeira lei. É desta sorte que o povo delegará na urna o que possuía nas armas" (Apontamentos..., ob. cit., p. 169).

37 CAPELA, José Viriato, A revolução do Minho de 1846. Os difíceis..., ob. cit.

${ }^{8}$ FERREIRA, Maria de Fátima Sá e Melo, ob. cit.
} 
também certo que nos concelhos de grande ou média dimensão, que não coincidiam com a comunidade de habitantes, a grande maioria da população não participava na "eleição" dos cargos concelhios nem, por maioria de razão, fazia parte das "listas de elegíveis". O carácter oligárquico de grande parte das administrações municipais ter-se-á mesmo acentuado, nos finais do período39.

Assim, mesmo que o auto-governo fosse uma aspiração de muitas comunidades rurais baseadas em experiências mais ou menos próximas no tempo ou no espaço, nada permite igualmente supor que a agitação em torno dos poderes locais e da sua eleição durante a Maria da Fonte fosse apenas mais uma forma de aspiração do regresso das "leis velhas"40. Pelo contrário, a reivindicação de que "todos votem nas próximas eleições", considerada uma "exigência intolerável" dos "povos" pelas autoridades, aparece como uma exigência ditada pelo cruzamento de temas da modernidade política com antigas aspirações das populações rurais. Ou seja, como um resultado da reelaboração de alguns dos novos tópicos da política moderna à luz de antigas aspirações ou experiências tendo como resultado aquilo que tem sido designado por vários autores como "política popular"41.

Poderia, pois, dizer-se que, num período de transição e mudança como foi o séc. XIX, sobretudo na sua primeira metade, a circulação de doutrinas,

\footnotetext{
39 MONTEIRO, Nuno Gonçalo, “Os poderes locais no Antigo Regime”, César OLIVEIRA (dir.), História dos Municipios e do Poder local (dos finais da Idade-Média à União Europeia), Mem Martins, Círculo de Leitores, 1996; FERNANDES, Paulo Jorge da Silva, Elites e finanças municipais em Montemor-o-Novo do Antigo Regime à Regeneração (1816-1851), Câmara Municipal de Montemor-o-Novo, 1999.

40 Tal não significa que algumas situações do passado não fossem vistas com nostalgia nomeadamente quando se contrapunham os custos dos cargos administrativos e judiciais do presente a um passado de que eles estariam ausentes. No entanto, como bem sublinhou Nuno Monteiro, já no Antigo Regime "o governo autónomo da pequena comunidade local associa a auto-regulação em matéria judicial com os altos custos da justiça oficial e letrada, cujo peso denuncia ferozmente". Como o mesmo autor muito justamente observou, queixas semelhantes ecoam na carta do Padre Casimiro à Rainha quando apela à reposição da "demarcação antiga das justiças" (MONTEIRO, Nuno Gonçalo, ob. cit., p. 127).

41 A noção de "política popular" tem sido desenvolvida a partir da análise político-cultural dos conflitos protagonizados pelas camadas populares rurais e urbanas na Europa pré-industrial. Foram particularmente importantes os contributos do grupo dos chamados "marxistas britânicos" em particular as obras de E. P. Thompson (1991) e Georges Rudé (1980). A historiografia francesa também tem trabalhado esta noção que começou por ser debatida por Raymond Huard (1984) e deu mais tarde origem a um trabalho mais aprofundado e polémico de Roger Dupuy (2002). Para uma visão mais actualizada ver CARDOSO, António Monteiro, “" Autogoverno » e « moralismo igualitário ». Política Popular em Portugal no século XIX”, José NEVES (org.), Como se faz um povo? Ensaios em História Contemporânea de Portugal, Lisboa, Edições Tinta-da-China, 2010.
} 
princípios e valores entre as elites e as camadas populares, mesmo as menos abastadas do mundo rural, teve todas as condições para se intensificar e alargar ao próprio ritmo em que se difundiam e viviam novas experiências políticas, sociais e culturais. As populações rurais, tal como outros grupos sociais, aceitaram umas e rejeitaram outras de acordo com as suas próprias conveniências, expectativas e necessidades.

Está hoje suficientemente demonstrado que, mesmo quando pareciam guiados apenas pelo "atavismo das suas crenças ancestrais", como quando se opuseram às leis da saúde pública e à construção de cemitérios, os camponeses estavam também a opor-se ao esvaziamento de funções das confrarias que, pelo menos no Norte do país, representavam uma forte expressão de sociabilidade, identidade e economia de muitas comunidades rurais ${ }^{42}$.

Explicar os conflitos do mundo rural com base no apego à tradição das populações camponesas, ou no seu atavismo, ou por um qualquer impulso permanente de "resistência à mudança”, não nos leva, assim, muito longe.

Historiadores de tão grande relevo como E. P. Thompson procederam à sua crítica de uma forma vigorosa e aprofundada e contrapuseram-lhe outras ferramentas analíticas como a noção de “economia moral”, utilizada há já muitos anos por este mesmo autor para a análise dos motins de subsistência na Inglaterra do séc. XVIII43, mostrando também como a evocação de antigos costumes podia ser sobretudo um instrumento de reinvindicação de novos direitos.

No que se refere ao séc. XIX é impossível ignorar também a forma como a implantação dos modernos regimes liberais, as lutas que lhes estiveram associadas e as novas práticas políticas que com eles emergiram influenciaram a linguagem e a expressão de novos e velhos conflitos.

42 CAPELA, José Viriato; BORRALHEIRO, José, A Maria da Fonte na Póvoa do Lanhoso. Novos documentos para a sua história, Póvoa do Lanhoso, Ca mara Municipal da Póv voa de Lanhoso 1996; FERREIRA, Maria de Fátima Sá e Melo, ob. cit.

43 THOMPSON, E. P., Costumes em Comum. Estudos sobre a cultura popular tradicional, São Paulo, Campo das Letras, 1999 ( $1^{\mathrm{a}}$ ed. inglesa, 1991). (O estudo aqui referido, "A economia moral da multidão inglesa no século XVIII" foi publicado pela primeira vez em 1971 na revista Past and Present, $\mathrm{n}^{\mathrm{0}}{ }^{50}$ ). 
A análise da politização do mundo rural através do processo de nacionalização da política, equacionada primeiro por Maurice Agulhon em La Republique au Village e depois por Eugene Weber em Peasants into Frenchmen 44 , e prosseguida com grande dinamismo por outros historiadores 45 , ao constituir um ponto de observação privilegiado da interacção entre o local e o nacional e entre novos e velhos reportórios de acção colectiva, parece uma perspectiva bastante mais útil para pensar a conflitualidade rural no quadro da modernização política oitocentista. Os conflitos registados nas provinciais portuguesas no ano de 1846, pelas características já enunciadas e também pela sua dimensão nacional, aparecem, neste contexto, como um terreno especialmente propício a esta indagação.

\section{Fontes e bibliografia}

AGULHON, Maurice, La République au village, Paris, Plon, 1970.

ALMEIDA, Pedro Tavares de, Eleições e caciquismo no Portugal oitocentista (1868-1890), Lisboa, Difel, 1991.

Apontamentos para a história da revolução do Minho em 1846 ou da Maria da Fonte, escriptos pelo Padre Casimiro finda a guerra em 1847, Lisboa, Edições Rolim, s/d. (Prefácio de José Manuel Sobral).

BRANCO, Rui Miguel, “A introdução do sistema métrico-decimal em Portugal”, Pedro Tavares de ALMEIDA e Rui Miguel C. BRANCO (coords.), Burocracia, Estado e território. Portugal e Espanha (séculos XIX - XX), Lisboa, Livros Horizonte, 2007.

BRISSOS, José, A insurreição miguelista nas resistências a Costa Cabral (1842-1847), Lisboa, Edições Colibri, 1997.

CAPELA, José Viriato; BORRALHEIRO, José, A Maria da Fonte na Póvoa do Lanhoso. Novos documentos para a sua história, Póvoa do Lanhoso, Ca mara Municipal da Pó voa de Lanhoso,1996.

CAPELA, José Viriato, A revolução do Minho de 1846. Os difíceis anos da implantação do liberalismo, Braga, Governo Civil de Braga, 1997.

CAPELA, José Viriato, A revolução do Minho de 1846 segundo os relatórios de Silva Cabral e Terena José, Porto, Afrontamento, 1999.

CARDOSO, António Monteiro, "«Autogoverno » e « moralismo igualitário », Política Popular em Portugal no século XIX”. José NEVES (org.), Como

\footnotetext{
44 WEBER, Eugene, Peasants into Frenchmen. The modernization of rural France,1870-1914, Stanford University Press, 1976.

45 PÉCOUT, Gilles, "La politisation des paysans au XIX e siècle. Réflexions sur l'histoire politique des campagnes", Histoire et sociétés rurales, $\mathrm{n}^{\circ}$ 2, 1994, pp. 91-125; La politisation des campagnes au XIXe siècle. France, Italie, Espagne et Portugal, Ecole Française de Rome, 2000.
} 
se faz um povo? Ensaios em História Contemporânea de Portugal, Lisboa, Edições Tinta-da-China, 2010.

CASTELO-BRANCO, Camilo, A Maria da Fonte. A propósito dos Apontamentos para a História da Revolução do Minho em 1846 publicados recentemente pelo Reverendo Padre Casimiro, celebrado chefe da insurreição popular, Porto, Livraria Civilização, 1885.

CUNHA, Carlos Guimarães da, A "Janeirinha e o Partido Reformista. Da revoluçãp de Janeiro de 1868 ao pacto da Granja, Lisboa, Edições Colibri, 2003.

DUPUY, Roger, La politique du Peuple, Paris, Albin Michel, 2002.

ESTEVÃO, João Antunes, "Guerrilhas na Serra da Lameira e guerrilhas de Fafe. Antropologia da violência rural", Actas das II Jornadas de História Local, Fafe, Câmara Minicipal de Fafe, 1998.

FEIJÓ, Rui Graça, Liberalismo e Transformação Social, Lisboa, Editorial Fragmentos, 1992.

FERNANDES, Paulo Jorge da Silva, Elites e finanças municipais em Montemor-o-Novo do Antigo Regime à Regeneração (1816-1851), Câmara Municipal de Montemor-o-Novo, 1999.

FERREIRA, Maria de Fátima Sá e Melo, Rebeldes e Insubmissos. Resistências populares ao liberalismo, 1834-1844, Porto, Afrontamento, 2002.

História da coragem feita com o coração. Actas do "Congresso Maria da Fonte 150 anos. 1846/1996”, Póvoa do Lanhoso, Câmara Municipal da Póvoa do Lanhoso, 1996.

HUARD, Raymond, "Existe-t-il une 'politique populaire'?", Jean NICOLAS (dir.), Mouvements populaires et conscience sociale, XVIe-XIXe siècles, Paris, Maloine, 1985, pp. 57-68.

JUSTINO, David, A formação do espaço económico nacional-Portugal, 18101913, Lisboa, Editorial Vega, 1988-1989, 2 vols.

JUSTINO, David, Fontismo: liberalismo numa sociedade iliberal, Lisboa, D. Quixote, 2016.

La politisation des campagnes au XIXe siècle. France, Italie, Espagne et Portugal, Ecole Française de Rome, 2000.

LOUSADA, Maria Alexandre; FERREIRA, Maria de Fátima Sá e Melo, D. Miguel, Mem Martins, Círculo de Leitores, 2006.

MONTEIRO, Nuno Gonçalo, "Os poderes locais no Antigo Regime", César OLIVEIRA (dir.), História dos Municipios e do Poder local (dos finais da Idade-Média à União Europeia), Mem Martins, Círculo de Leitores, 1996.

OLIVEIRA, Luísa Tiago de, "A Maria da Fonte e a Patuleia. Alguns problemas", Ler História, no 16, 1989, pp. 159-174.

PALACIOS CEREZALES, Diego, Estranhos corpos políticos: protesto $e$ mobilização no Portugal do século XIX, Lisboa, Edições Unipop, 2014. 
PÉCOUT, Gilles, "La politisation des paysans au XIX e siècle. Réflexions sur l'histoire politique des campagnes", Histoire et sociétés rurales, $\mathrm{n}^{\circ}{ }_{2}$, segundo semestre 1994, pp. 91-125.

PEREIRA, Miriam Halpern, "A Maria da Fonte entre o saber e a dúvida", História da coragem feita com o coração. Actas do "Congresso Maria da Fonte 150 anos. 1846/1996”, Câmara Municipal da Póvoa do Lanhoso, 1996.

RUDÉ, Georges, Ideologia e protesto popular, Rio de Janeiro, Zahar, $1992\left(1^{\text {a }}\right.$ ed. inglesa, 1980).

THOMPSON, E. P., Costumes em Comum. Estudos sobre a cultura popular tradicional, São Paulo, Campo das Letras, 1999. (1 $1^{\mathrm{a}}$ ed. inglesa, 1991).

WEBER, Eugene, Peasants into Frenchmen. The modernization of rural France, 1870-1914, Stanford University Press, 1976. 


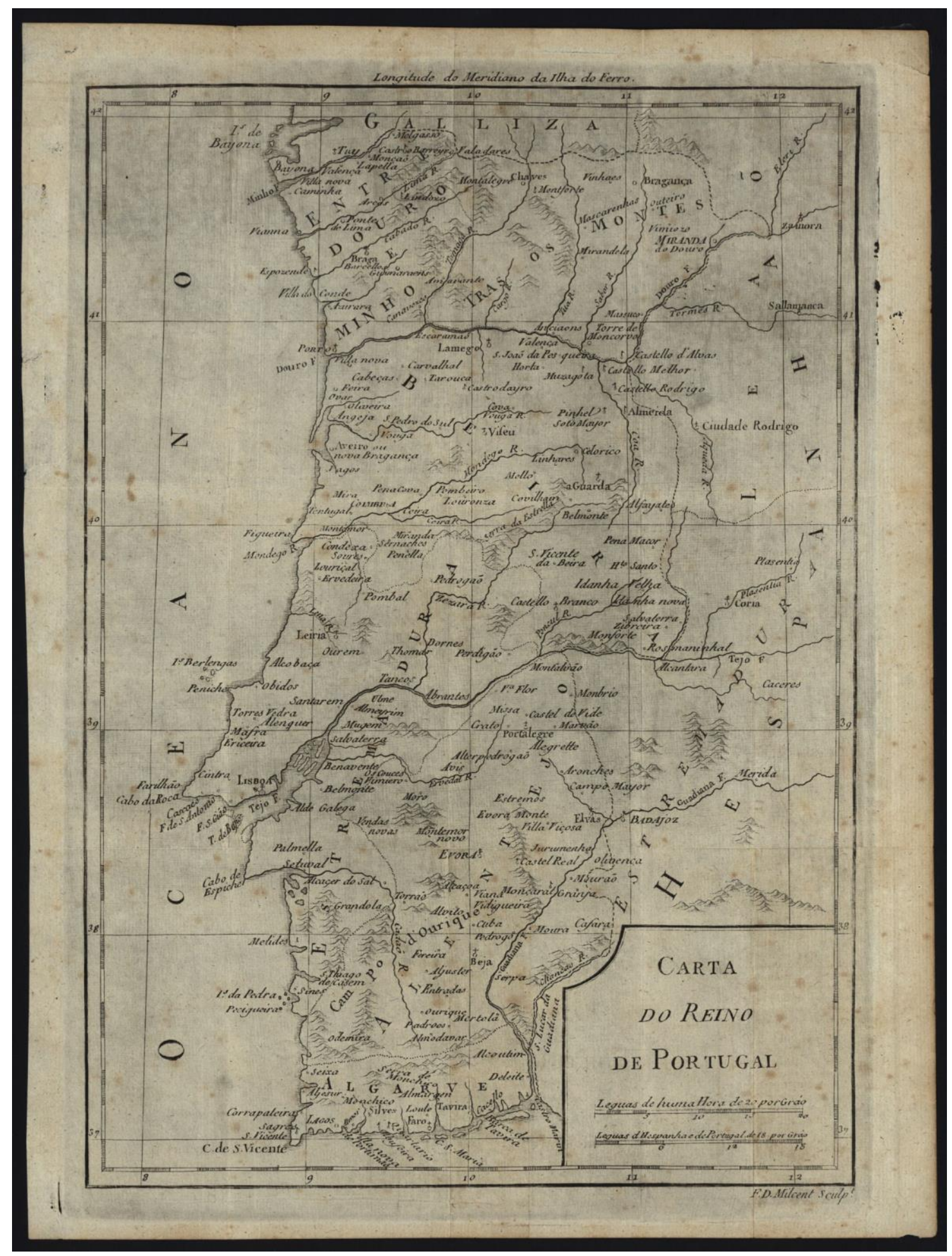

Carta do Reino de Portugal, ca 1780. F. D. Milcent, sculpt.. - Escala [ca 1:170000o], 20 Leguas de huma Hora de 20 por Gráo = [6,40 cm]. - 1 mapa : gravura, p\&b ; 36x25 cm, em folha de 38 x28 cm. Biblioteca Nacional de Portugal. Disponible en: http://purl.pt/1589/3/ 
Distritos em 1835

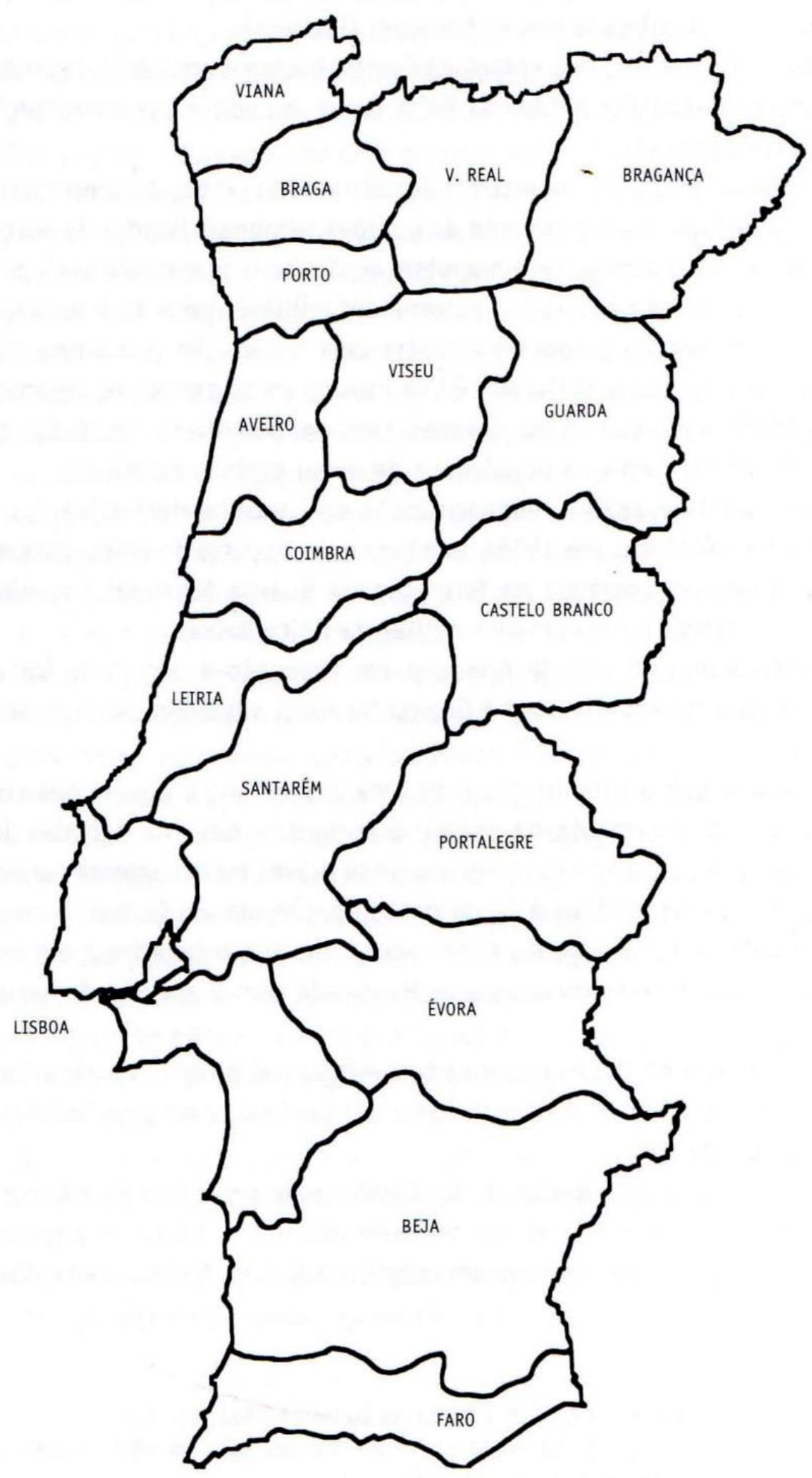

Fonte: J. António Santos, Regionalização, Processo Histórico, Livros Horizonte, 1985, p. 85. Tomado de Maria de Fátima Sá e Melo FERREIRA, Rebeldes e Insubmissos. Resistências populares ao liberalismo, 1834-1844, Porto, Afrontamento, 2002, p. 128. 